\title{
Anti-apoptosis effect of heme oxygenase-1 on lung injury after cardiopulmonary bypass
}

\author{
Wei Sheng ${ }^{1 \#}$, Haiqin Yang ${ }^{2 \#}$, Zhaozhuo Niu ${ }^{1}$, Hong Yin ${ }^{1}$ \\ ${ }^{1}$ Department of Cardiovascular Surgery, Qingdao Municipal Hospital, Medical College of Qingdao University, Qingdao 266071, China; ${ }^{2}$ Department \\ of Mental Intervention, Qingdao Preferential Hospital, Qingdao 266071, China \\ Contributions: (I) Conception and design: W Sheng, H Yang, H Yin; (II) Administrative support: Z Niu; (III) Provision of study materials or patients: \\ W Sheng, Z Niu, H Yin; (IV) Collection and assembly of data: H Yang, H Yin; (V) Data analysis and interpretation: W Sheng, H Yang, H Yin; (VI) \\ Manuscript writing: All authors; (VII) Final approval of manuscript: All authors. \\ "These authors contributed equally to this work as co-first authors. \\ Correspondence to: Hong Yin, MM. Department of Cardiovascular Surgery, Qingdao Municipal Hospital, Medical College of Qingdao University, \\ Donghai Zhong Road No. 5, Qingdao 266071, China. Email: yinhongyh@126.com.
}

Background: This study aimed to investigate the anti-apoptosis effects of heme oxygenase-1 (HO-1) on lung injury (LI) after cardiopulmonary bypass (CPB) and its probable mechanisms.

Methods: One hundred and forty-four male Wistar rats were divided into 3 groups randomly: group A (control group), group B (cobalt protoporphyrin, CoPP), and group C [CoPP plus zinc protoporphyrin $(\mathrm{ZnPP})]$. Lung tissues were harvested at different time: before CPB (T0), 0 min after CPB (T1), $2 \mathrm{~h}$ after CPB (T2), 6 h (T3), 12 h (T4), and 24 h (T5).

Results: The HO-1 protein expressions in lung tissue in group B were higher than those in group A and group $\mathrm{C}$ in any given time, and the same as HO-1 activity $(\mathrm{P}<0.05)$. The expressions of $\mathrm{Bcl}-2$ protein in group B at all time point after bypass were higher than those in group A and group $\mathrm{C}$, and the difference was statistically significant $(\mathrm{P}<0.05)$. Apoptosis index $(\mathrm{AI})$ in group $\mathrm{B}$ at any time point after bypass were lower than those in group A and group $\mathrm{C}(\mathrm{P}<0.05)$.

Conclusions: CoPP can significantly increase the expression of HO-1 protein in lung tissue. HO-1 is still highly expressed after $\mathrm{CPB}$, so as to play an important part in anti-apoptosis, and reduce LI.

Keywords: Heme oxygenase-1 (HO-1); cardiopulmonary bypass (CPB); lung injury (LI); cell apoptosis

Submitted Nov 07, 2019. Accepted for publication Feb 14, 2020.

doi: $10.21037 /$ jtd.2020.03.48

View this article at: http://dx.doi.org/10.21037/jtd.2020.03.48

\section{Introduction}

Heme oxygenase-1 (HO-1), also called heat shock protein 32 (Hsp32), is an inducible enzyme that can convert heme into carbon monoxide (CO), biliverdin, and free iron. HO-1 is present at low levels in many tissues and is highly upregulated by numerous stimuli, such as heme, heavy metals, reactive oxygen species and inflammatory cytokines. Recent findings reported that HO-1 and its metabolites exerted anti-inflammatory, antioxidative $(1,2)$, antiproliferative and antiapoptotic activities $(3,4)$.

Lung injury (LI) is one of the earliest and most common complications which are difficult to treat in cardiac surgery, especially after undergoing cardiopulmonary bypass (CPB) $(5,6)$. Many findings reported that endogenous induction of HO-1 played an important protective effect on cells and tissues against injuries related to lung diseases $(1,7,8)$. Most cardiac surgery requires a non-physiological process such as CPB or deep hypothermic circulatory cardiac arrest. Little research has been done in this field which whether HO-1 can still play a protective effect in lung tissue after such a complex pathophysiological process, and what its specific mechanism is if it still plays a protective role. In our study, we used cobalt protoporphyrin as an inducer of HO-1 and 


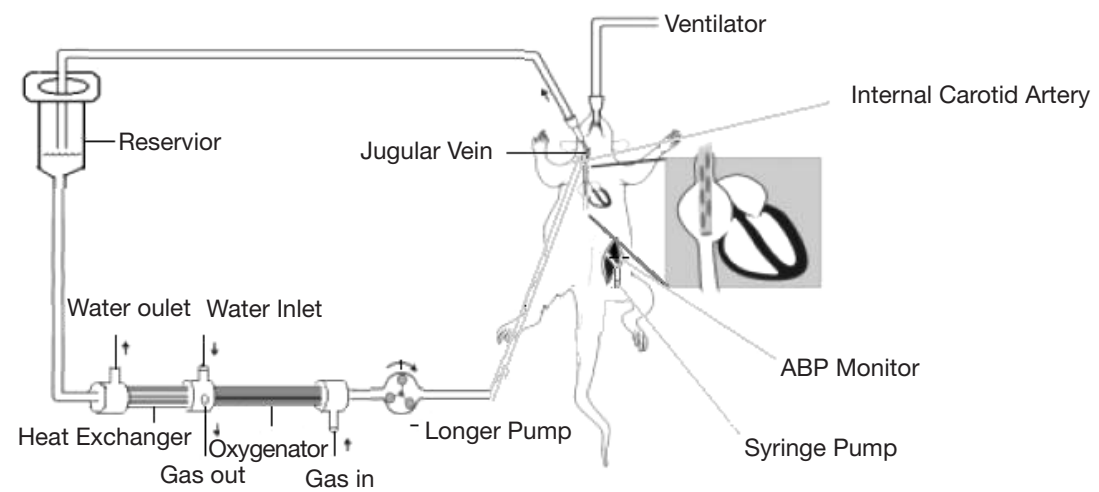

Figure 1 The establishment of the modified model of CPB-induced lung injury. ABP, arterial blood pressure; CPB, cardiopulmonary bypass.

evaluated whether HO-1 still played its anti-apoptotic effect on lung tissue after CPB. We used zinc protoporphyrin $(\mathrm{ZnPP})$ as the specific inhibitor of $\mathrm{HO}-1$ and assessed its effect in the process. We also tried to explore the possible mechanism of its protective effect.

\section{Methods}

\section{Animals}

One hundred and forty-four male Wistar rats (14-17 weeks of age) weighing 250-350 g were purchased from the Laboratory Animal Center of Qingdao Institute for Food and Drug Control (Qingdao, China). All protocols were approved by the Qingdao Institute for Biochemical Drug Control Animal Care and Use committee and by the Ethics Committee of Qingdao Municipal hospital affiliated to Qingdao University (Qingdao, China), and the care and handling of the animals were in accordance with the Guide for the Care and Use of Laboratory Animals of the National Institutes of Health.

\section{Animals experimental protocol}

The experimental animals were randomly divided into three groups with 48 rats per group as follows: (I) group A: (control group), experimental rats received intraperitoneal injection of normal saline 24 hours before CPB; (II) group B: (CoPP group), experimental rats received intraperitoneal injection of CoPP at a dose of $5 \mathrm{mg} / \mathrm{kg}$ 24 hours before $\mathrm{CPB}$, and other procedures were the same as the control group; (III) group C: (CoPP plus ZnPP group), experimental rats received intraperitoneal injection of $\mathrm{CoPP}$ at a dose of $5 \mathrm{mg} / \mathrm{kg}$ and $\mathrm{ZnPP}$ at a dose of $5 \mathrm{mg} / \mathrm{kg}$
24 hours before $\mathrm{CPB}$, and other procedures were the same as the control group. Copp and Znpp were purchased from were purchased from Sigma-Aldrich (St. Louis, MO, USA).

\section{Establishment of the modified rat CPB model}

Animals were anesthetized by intraperitoneal injection of droperidol (0.25 mg/kg, Yookon, Beijing, China), fentanyl $(0.02 \mathrm{mg} / \mathrm{kg}$, Humanwell Pharmaceutical Co., Ltd., Hubei, China) and ketamine $(5 \mathrm{mg} / \mathrm{kg}$, Hengrui Medicine, Jiangsu, China), intubated with a $14 \mathrm{G}$ Intravenous catheter (B. Braun Melsungen AG, Germany) and connected to a small animal ventilator RWD407 (RWD Life Science Co., Shenzhen, China). CPB was established via right internal carotid artery with a $22 \mathrm{G}$ Intravenous catheter (B. Braun Melsungen AG, Germany) and internal jugular vein with a $16 \mathrm{G}$ single lumen central venous catheter (Arrow, Reading, Pennsylvania, USA) (9). Activated clotting time (ACT) was maintained above 480 seconds during CPB. The pulmonary artery was freed and exposed after the CPB. Mean arterial pressure was maintained $55-60 \mathrm{mmHg}$ during CPB. The pulmonary artery was cross clamped 10 minutes after CPB. Meanwhile, the mechanical ventilation was stopped. The pulmonary artery cross clamp was released 50 minutes after parallel circulation, then the jugular vein catheter was inserted into the right atrium and then the mechanical ventilation was initiated. Gradual rewarming was performed with anal temperature reaching $36.0^{\circ} \mathrm{C}$ in 30 minutes, and then we ended the CPB. The establishment of the modified rat model of CPB-induced LI was showed in Figure 1. The lung tissues were harvested at different time: before $\mathrm{CPB}$ (T0), end of CPB (T1), 2 hours after CPB (T2), 6 hours after CPB (T3), 12 hours after CPB (T4), 24 hours after CPB (T5). Lung tissue specimens (right upper lung) of the 
rats were fixed by $4 \%$ of paraformaldehyde (Sigma-Aldrich, St. Louis, MO, USA), embedded with paraffin and then cut into $5 \mu \mathrm{m}$ sections by automatic histotome (Leica RM 2255, leica biosystem nussloch Gmbh, Heidelberger, Germany).

\section{Immunobistochemistry}

Immunohistochemical staining was performed by using the Strept Avidin Biotin Peroxidase Complex kit purchased from Beijing Zhongshan Golden Bridge Biotechnology Co., Ltd. (Beijing, China). The positive expression was mainly in the cytomembrane or cytoplasm, presenting as brownish yellow granules. The electron microscope (Olympus PM-30, Japan) image were then evaluated and quantified by using the image-Pro Plus 12.0 software. The mean optical density (MOD) of positive expression was measured in five different visual fields at random. The intensity of positive expression of HO-1 protein was expressed by the MOD value of five different visual fields. Specifically as follow: immunohistochemistry was performed after blocking endogenous peroxidase activity with $3 \% \mathrm{H}_{2} \mathrm{O}_{2}$ for $10 \mathrm{~min}$, and non-specific protein binding with using $5 \%$ Bovine Serum Albumin (BSA) at room temperature $\left(37^{\circ} \mathrm{C}\right)$ for $25 \mathrm{~min}$. Sections were then incubated with anti-HO-1 antibody (1:100 dilution; SantaCruz Biotechnology, CA, USA) overnight at $4{ }^{\circ} \mathrm{C}$. After three rinses of $3 \mathrm{~min}$ with phosphate buffer solution (PBS), sections were incubated with diluted Biotinlyated IgG secondary antibody (SantaCruz Biotechnology, CA, USA) at room temperature $\left(37^{\circ} \mathrm{C}\right)$ for $20 \mathrm{~min}$ in humidified chamber. Following three rinses of 2 min with PBS, the slides were then stained utilizing the Strept Avidin-Biotin Complex (SABC) method. Sections were then stained with diaminobenzidine (DAB), after development, the slides were counterstained with hematoxylin. The immunoreaction was evaluated with the Imagepro-Plus 12.0 which had been programmed to determine the MOD of positive areas. The immunohistochemical method for the determination of Bcl-2 protein expression was the same as that of HO-1.

\section{HO-1 activity}

The bilirubin levels are detected to evaluate the activity of HO-1 in lung tissue according to the principle that heme is degraded by HO- 1 to form carbon monoxide (CO) and bilirubin. The bilirubin levels in lung tissue are detected by using the dual-wavelength atomic absorption spectrophotometer (Nanjing Feile Instrument Co., Ltd.,
Nanjing, China). One gram of lung tissue is rinsed with cold potassium dihydrogen phosphate buffering solution $(0.1 \mathrm{~mol} / \mathrm{L}, \mathrm{pH}=7.4)$, and then 4-fold volume of the same buffering solution was put into the lung tissue. Then lung tissue was homogenized with tissue homogenizer and centrifuged in a high-speed centrifuge for 15 minutes $(15,000 \mathrm{r} / \mathrm{min})$ under low temperature $\left(4^{\circ} \mathrm{C}\right)$. The lipid layer was then removed and the remaining supernatant solution was collected by eppendorf (EP) tube, and then stored in a low temperature refrigerator at $-80{ }^{\circ} \mathrm{C}$. Forty $\mu \mathrm{L}$ of $2 \mathrm{mmol} / \mathrm{L}$ haemoglobin, $1.8 \mathrm{~mL}$ of potassium dihydrogen phosphate solution ( $0.1 \mathrm{~mol} / \mathrm{L}, \mathrm{pH}=7.4), 40 \mu \mathrm{L}$ of $4.5 \mathrm{mmol} / \mathrm{L}$ reductive coenzyme II, and $20 \mu \mathrm{L}$ normal liver homogenate supernatant were added to $20 \mu \mathrm{L}$ of lung tissue homogenate supernatant after centrifugation. Then it was allowed for reaction for $10 \mathrm{~min}$ at $37^{\circ} \mathrm{C}$ without light exposure, and then it was placed on ice to stop the reaction. Samples without reductive coenzyme II were selected as blank control, blank control group and experimental group were made into two parts respectively. Bilirubin level was measured by using dual-wavelength atomic absorption spectrophotometer at 464 and $530 \mathrm{~nm}$. The molar absorption coefficient for bilirubin is $40 \mathrm{~mol} / \mathrm{L} / \mathrm{cm}$. The unit of measurement was expressed by $\mathrm{pmol} / \mathrm{mg} / \mathrm{h}$.

\section{Terminal deoxynucleotidyl transferase-mediated dUTP nick-end labeling (TUNEL)}

Lung tissue apoptosis was detected by terminal deoxynucleotidyl transferase dUTP nick end labeling (TUNEL) assay using an In Situ Cell Death Detection kit (Roche Diagnostics, Indianapolis, IN, USA) according to the manufacturer's protocol. Lung tissues (right upper lung) were embedded in paraffin and cut into $5 \mu \mathrm{m}$ thick sections. After that step, the sections were dewaxed in xylene, rehydrated in ethanol and permeabilized with $0.1 \%$ Triton $\mathrm{X}-100$. Then, $3 \% \mathrm{H}_{2} \mathrm{O}_{2}$ was used to block endogenous peroxidase activity. Sections were incubated with Protease $\mathrm{K}(20 \mu \mathrm{g} / \mathrm{mL}, \mathrm{PH}=7.4)$ at $37{ }^{\circ} \mathrm{C}$ for $15 \mathrm{~min}$, and incubated with $50 \mu \mathrm{L}$ TUNEL reaction mixture at $37^{\circ} \mathrm{C}$ for $1 \mathrm{~h}$ and with $50 \mu \mathrm{L}$ converter POD for $30 \mathrm{~min}$. Finally, the sections were treated with $\mathrm{DAB}$ substrate. The stained sections were visualized via an Olympus microscope (Olympus PM-30, Japan). TUNEL-labeled positive cells stained with brownish yellow color in cell nucleus were apoptotic cells. The apoptotic index (AI) of lung tissue was calculated by the following method (10): apoptotic-positive cells in a total of 100 cells were counted by microscopic examination in 
Table 1 Measurement of the mean optical density of HO-1 protein expression in rat lung tissues in IHC ( $\bar{x} \pm \mathrm{s})$

\begin{tabular}{lcccccc}
\hline Group & T0 $(n=8)$ & $T 1(n=8)$ & $T 2(n=8)$ & $T 3(n=8)$ & $T 4(n=8)$ & T5 $(n=8)$ \\
\hline A $(n=48)$ & $0.1142 \pm 0.058$ & $0.1425 \pm 0.064^{\Delta}$ & $0.1852 \pm 0.070^{\Delta}$ & $0.1683 \pm 0.076^{\Delta}$ & $0.1518 \pm 0.065^{\Delta}$ & $0.1439 \pm 0.066^{\Delta}$ \\
B $(n=48)$ & $0.1820 \pm 0.067^{\star \#}$ & $0.2386 \pm 0.085^{\star \star \Delta}$ & $0.2873 \pm 0.091^{* \# \Delta}$ & $0.2578 \pm 0.084^{* \# \Delta}$ & $0.2375 \pm 0.087^{* \# \Delta}$ & $0.1849 \pm 0.072^{\star \# \Delta}$ \\
$C(n=48)$ & $0.1138 \pm 0.061$ & $0.1486 \pm 0.064^{\Delta}$ & $0.1917 \pm 0.082^{\Delta}$ & $0.1712 \pm 0.075^{\Delta}$ & $0.1572 \pm 0.069^{\Delta}$ & $0.1430 \pm 0.059^{\Delta}$ \\
\hline
\end{tabular}

${ }^{*}, \mathrm{P}<0.05$, compared with group $\mathrm{A}$ at the same time point; ${ }^{*}, \mathrm{P}<0.05$, compared with group $\mathrm{C}$ at the same time point; ${ }^{\Delta}, \mathrm{P}<0.05$, compared with TO (before CPB) in the same group.

five random fields (200x) as the AI.

\section{Statistical analysis}

Statistical analysis was carried out by using SPSS Base 17.0 statistical software (SPSS Inc, Chicago, IL, USA). The measurement data were tested for normality, normal distribution of measurement data was measured by mean \pm standard deviation, and one-way analysis of variance (ANOVA) and $t$-test were used to assess the differences between and within groups. A P value of less than 0.05 was considered to be statistically significant.

\section{Results}

\section{The expression levels of $\mathrm{HO}-1$ in rat lung tissues in IHC}

The expression of HO-1 protein in lung tissue were mainly on cell membrane and cytoplasm, positive cells were stained brownish yellow. As displayed by immunohistochemistry, HO-1 protein in lung tissue cells were mainly expressed in bronchiole epithelial cells, alveolar epithelial cells, and little in endothelial cells of blood vessels. The results showed higher expression of HO-1 protein in lung tissues of group $\mathrm{B}$ before and after $\mathrm{CPB}$ than those in group $\mathrm{A}$ and group $\mathrm{C}$ $(\mathrm{P}<0.05)$. The expression of HO-1 protein increased after $\mathrm{CPB}$ in rat lung tissue in each group, and it was expressed the most at T2 time point. As illustrated in Table 1 and Figure 2.

\section{Determination of HO-1 activity in lung tissue}

HO-1 activity increased in all groups of lung tissue after $\mathrm{CPB}$ with peak activity at $\mathrm{T} 2$ time point and then decreased. HO-1 activity in group B was higher than those in group $\mathrm{A}$ and group $\mathrm{C}$ before and after $\mathrm{CPB}(\mathrm{P}<0.05)$. HO-1 activity determination results were consistent with immunohistochemistry results of $\mathrm{HO}-1$ protein expression in rats lung tissues. Determination of HO-1 activity in lung tissues was illustrated in Table 2.

\section{The expression levels of Bcl-2 in rat lung tissues in IHC}

The difference of Bcl-2 protein expression levels in lung tissue cells of all groups before CPB (T0, Figure 3) were not statistically significant $(\mathrm{P}>0.05), \mathrm{Bcl}-2$ protein expression level decreased gradually after $\mathrm{CPB}$, to be lowest at $\mathrm{T} 2$ time point (Figure 4), and then increased. Bcl-2 protein expression was significantly higher in group B than those in groups A and group $\mathrm{C}(\mathrm{P}<0.05)$. Details were shown in Table 3 .

\section{Cell apoptosis in rat lung tissue}

The apoptotic cells were mainly distributed in alveolar epithelial cells, and a few in bronchial epithelial cells. There was no significant difference in AI of lung tissue in all of the groups before $\mathrm{CPB}$. AI increased gradually after $\mathrm{CPB}$, and reached its peak at $\mathrm{T} 2$ time point, and then decreased gradually. AI in group $\mathrm{B}$ was significantly lower than those in group $\mathrm{A}$ and group $\mathrm{C}(\mathrm{P}<0.05)$ at each time point after CPB. Details were shown in Table 4 and Figure 5.

\section{Discussion}

HO-1 provides an inducible defense mechanism that can be activated ubiquitously in cells and tissues in response to noxious stimuli, conferring cellular protection against injury inflicted by such stimuli (11). In present study, in the context of CPB-induced LI, we still confirmed this inducible defense mechanism. In present study, we confirmed that the expression of HO-1 protein was lower in lung tissue in all of the groups before $\mathrm{CPB}$, and this demonstrated that the expression of HO-1 protein was low under physiological circumstance. In present study, we established the modified rat $\mathrm{CPB}$ model. Consistent with other observations $(7,11)$, our results demonstrated HO-1 was strongly expressed 


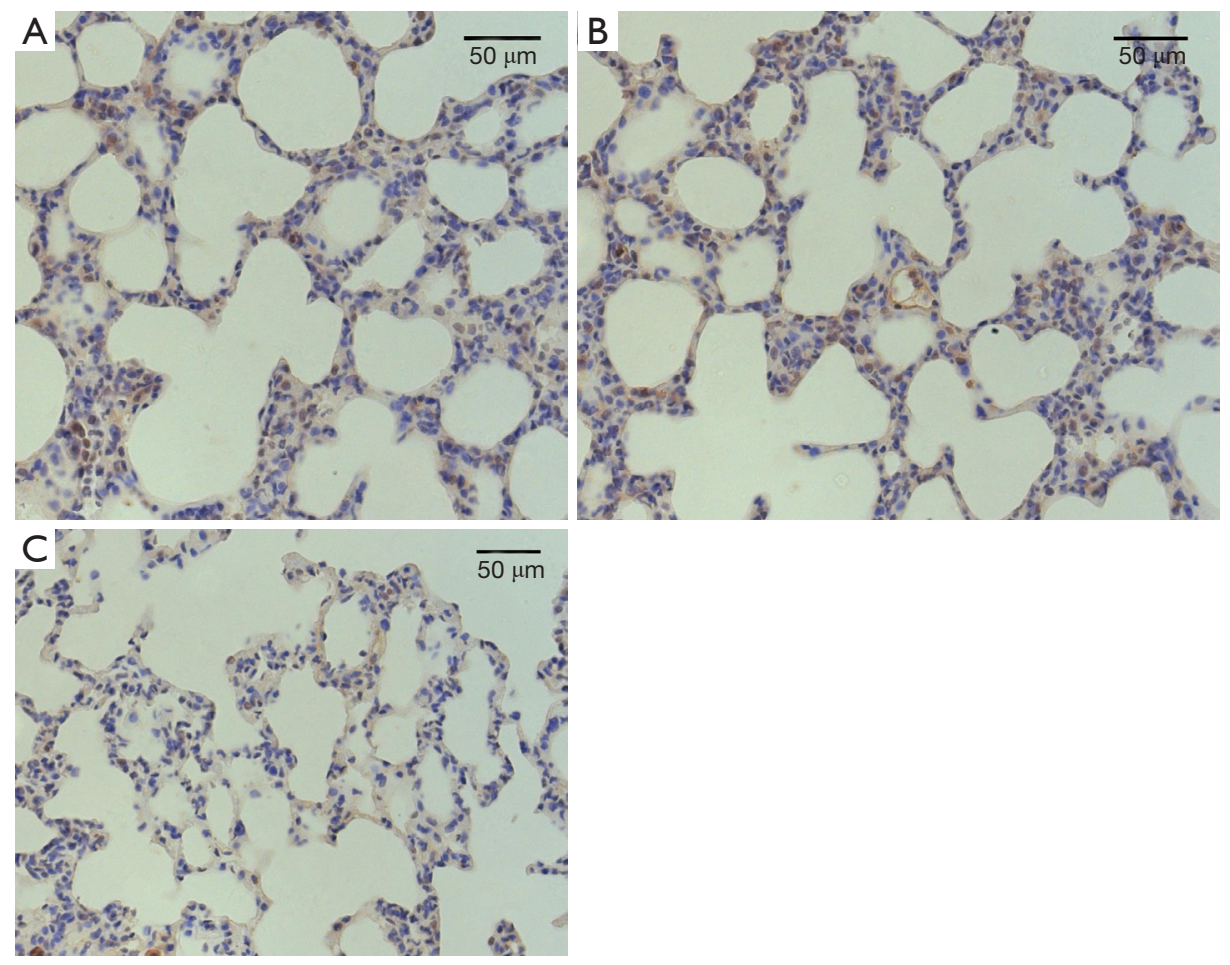

Figure 2 The expression of HO-1 protein in rat lung tissues in IHC at T2 time point (SABC, 200x). The positive cells displayed brownish yellow granules in cytoplasm. IHC, immunohistochemistry; SABC, Strept avidin biotin complex.

Table 2 Measurement of HO-1 activity in lung tissues $(\bar{x} \pm \mathrm{S})$

\begin{tabular}{|c|c|c|c|c|c|c|}
\hline Group & T0 $(n=8)$ & $\mathrm{T} 1(\mathrm{n}=8)$ & T2 $(n=8)$ & T3 $(n=8)$ & T4 $(n=8)$ & T5 $(n=8)$ \\
\hline$B(n=48)$ & $153 \pm 15^{\text {*\# }}$ & $346 \pm 29^{* \# \Delta}$ & $692 \pm 52^{\star \# \Delta}$ & $480 \pm 45^{\star \# \Delta}$ & $420 \pm 33^{* \# \Delta}$ & $317 \pm 30^{\star \# \Delta \Delta}$ \\
\hline$C(n=48)$ & $121 \pm 17$ & $138 \pm 18^{\Delta}$ & $161 \pm 20^{\Delta}$ & $145 \pm 16^{\Delta}$ & $140 \pm 15^{\Delta}$ & $129 \pm 12^{\Delta}$ \\
\hline
\end{tabular}

${ }^{*}, \mathrm{P}<0.05$, compared with group $\mathrm{A}$ at the same time point; ${ }^{\#}, \mathrm{P}<0.05$, compared with group $\mathrm{C}$ at the same time point; ${ }^{\Delta}, \mathrm{P}<0.05$, compared with T0 (before CPB) in the same group.

after CPB in the lung tissue in the CPB-induced LI model. Increased expression of $\mathrm{HO}-1$ in rat lung tissue after $\mathrm{CPB}$ showed that $\mathrm{CPB}$ brought about reperfusion injury and also activated the high expression of HO-1 as a protective mechanism at the same time.

As the oxidative catabolism process of Copp is similar to that of ferriporphyrin, it can effectively induce the high expression of HO-1 protein. Copp is recognized as a specific and efficient inducer of HO-1. ZnPP can inhibit HO-1 activity by inhibiting biliverdin production and interfering with CO production $(12,13)$. In present study, we pretreated rats which received $\mathrm{CPB}$ with $\mathrm{CoPP}$ in the absence or presence of $\mathrm{ZnPP}$ to explore the role of $\mathrm{HO}-1$ in CPB-induced LI. we confirmed that expression of HO-1 at all of the time points before and after CPB in the cobalt protoporphyrin (CoPP) group was significantly higher than that in the control group, and this demonstrated that cobalt protoporphyrin could induce the high expression of HO-1 protein and enhance HO-1 activity. Meanwhile, the expression of HO-1 in lung tissue in CoPP plus $\mathrm{ZnPP}$ group was the same as that in control group, and this indicated that zinc protoporphyrin suppressed the expression of HO-1 in lung tissues. It also had been found that CoPP pretreatment alleviated CPB-induced LI but $\mathrm{ZnPP}$ reversed the protective effect of CoPP in our study. This is consistent with results of previous studies $(12,14)$. 

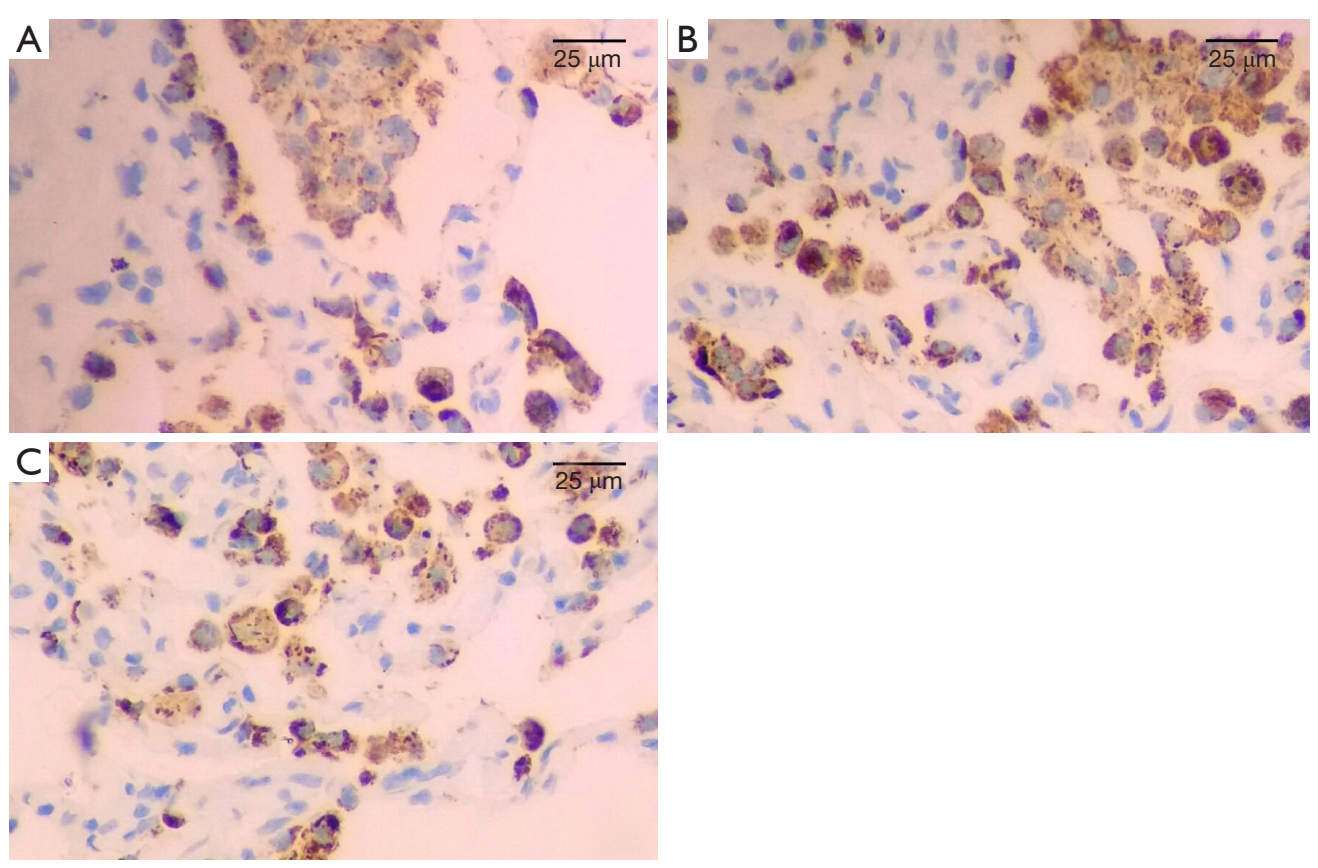

Figure 3 The expression of Bcl-2 in rat lung tissues in IHC at T0 time point (SABC, 400x). IHC, immunohistochemistry; SABC, Strept avidin biotin complex.
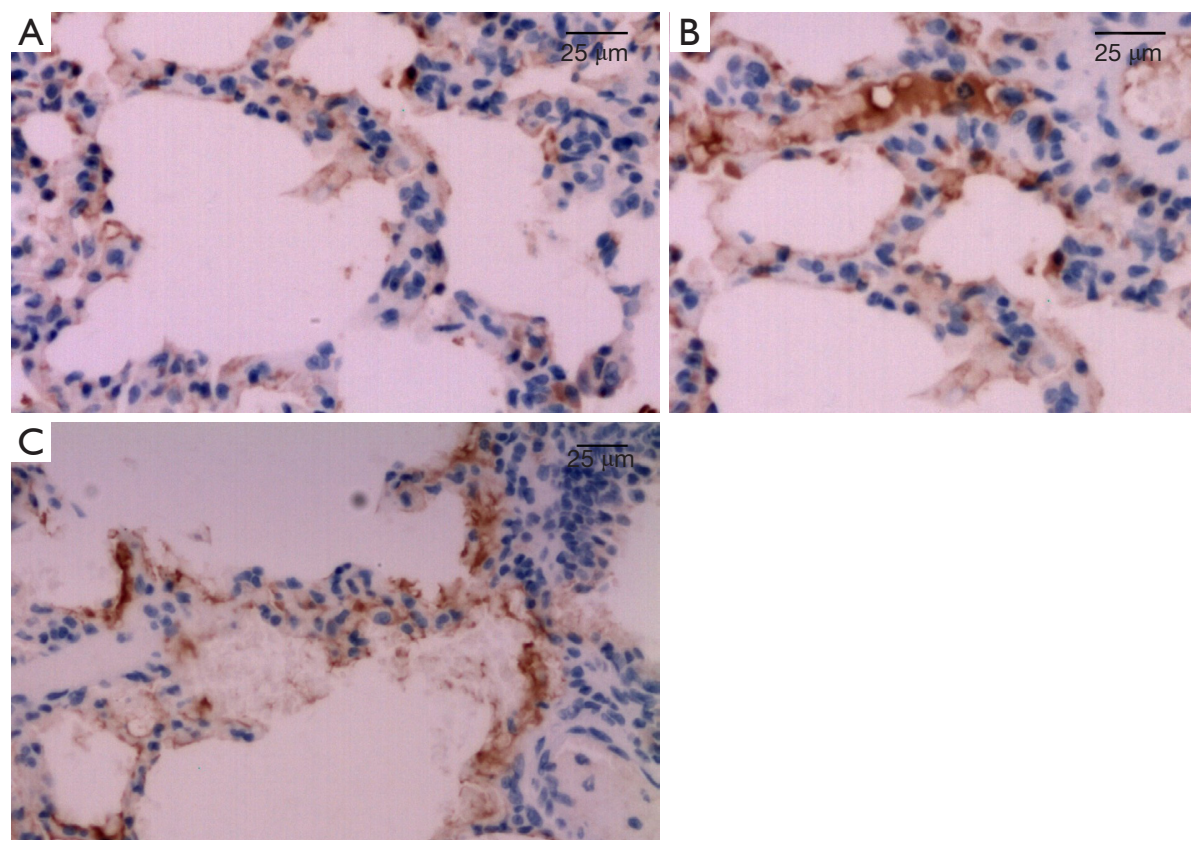

Figure 4 The expression of Bcl-2 in rat lung tissues in IHC at T2 time point (SABC, 400x). IHC, immunohistochemistry; SABC, Strept avidin biotin complex. 
Table 3 Measurement of the mean optical density of Bcl-2 protein expression in rat lung tissues in IHC $(\bar{x} \pm \mathrm{s})$

\begin{tabular}{|c|c|c|c|c|c|c|}
\hline Group & T0 $(n=8)$ & $\mathrm{T} 1(\mathrm{n}=8)$ & T2 $(n=8)$ & T3 $(n=8)$ & T4 $(n=8)$ & T5 $(n=8)$ \\
\hline$A(n=48)$ & $0.401 \pm 0.043^{*}$ & $0.202 \pm 0.022^{\wedge}$ & $0.168 \pm 0.019^{\wedge}$ & $0.196 \pm 0.020^{\wedge}$ & $0.212 \pm 0.018^{\mathbb{A}}$ & $0.228 \pm 0.023^{\wedge}$ \\
\hline$B(n=48)$ & $0.432 \pm 0.046^{*}$ & $0.287 \pm 0.031^{\# \Delta \Delta}$ & $0.239 \pm 0.021^{\# \Delta \Delta}$ & $0.268 \pm 0.026^{\# \Delta \Delta}$ & $0.291 \pm 0.027^{\# \Delta \Delta}$ & $0.308 \pm 0.028^{\# \Delta \Delta}$ \\
\hline$C(n=48)$ & $0.415 \pm 0.042^{*}$ & $0.209 \pm 0.021^{\wedge}$ & $0.171 \pm 0.016^{\Delta}$ & $0.189 \pm 0.019^{4}$ & $0.214 \pm 0.017^{\mathbf{A}}$ & $0.225 \pm 0.021^{\wedge}$ \\
\hline
\end{tabular}

${ }^{*}, \mathrm{P}>0.05$, compared with each other at T0 time point; ${ }^{\#}, \mathrm{P}<0.05$, compared with group $\mathrm{A}$ at the same time point; ${ }^{\Delta}, \mathrm{P}<0.05$, compared with group $\mathrm{C}$ at the same time point; ${ }^{\wedge}, \mathrm{P}<0.05$, compared with T0 (before CPB) in the same group.

Table 4 Measurement of lung tissue apoptosis index in each group $(\bar{x} \pm s)$

\begin{tabular}{|c|c|c|c|c|c|c|}
\hline Group & T0 $(n=8)$ & $\mathrm{T} 1(\mathrm{n}=8)$ & T2 $(n=8)$ & T3 $(n=8)$ & $\mathrm{T} 4(\mathrm{n}=8)$ & T5 $(n=8)$ \\
\hline$A(n=48)$ & $1.21 \pm 0.22^{*}$ & $10.37 \pm 0.49^{\Lambda}$ & $14.26 \pm 0.75^{\mathbf{\Lambda}}$ & $11.83 \pm 0.55^{\boldsymbol{\Lambda}}$ & $9.21 \pm 0.52^{\mathbf{\Lambda}}$ & $6.85 \pm 0.46^{\mathbf{A}}$ \\
\hline$B(n=48)$ & $1.18 \pm 0.19^{\star}$ & $4.59 \pm 0.31^{\# \Delta \Delta}$ & $7.85 \pm 0.41^{\# \Delta \Delta}$ & $5.27 \pm 0.38^{\# \Delta \Delta}$ & $4.21 \pm 0.34^{\# \Delta \Delta}$ & $2.76 \pm 0.28^{\# \Delta \Delta}$ \\
\hline$C(n=48)$ & $1.19 \pm 0.21^{*}$ & $9.82 \pm 0.51^{\wedge}$ & $13.73 \pm 0.69^{\Delta}$ & $10.62 \pm 0.53^{\wedge}$ & $8.79 \pm 0.53^{\wedge}$ & $6.12 \pm 0.43^{\Delta}$ \\
\hline
\end{tabular}

*, P>0.05, compared with each other at T0 time point; ", $\mathrm{P}<0.05$, compared with group $\mathrm{A}$ at the same time point; ${ }^{\Delta}, \mathrm{P}<0.05$, compared with group $\mathrm{C}$ at the same time point; ${ }^{\wedge}, \mathrm{P}<0.05$, compared with T0 (before CPB) in the same group.

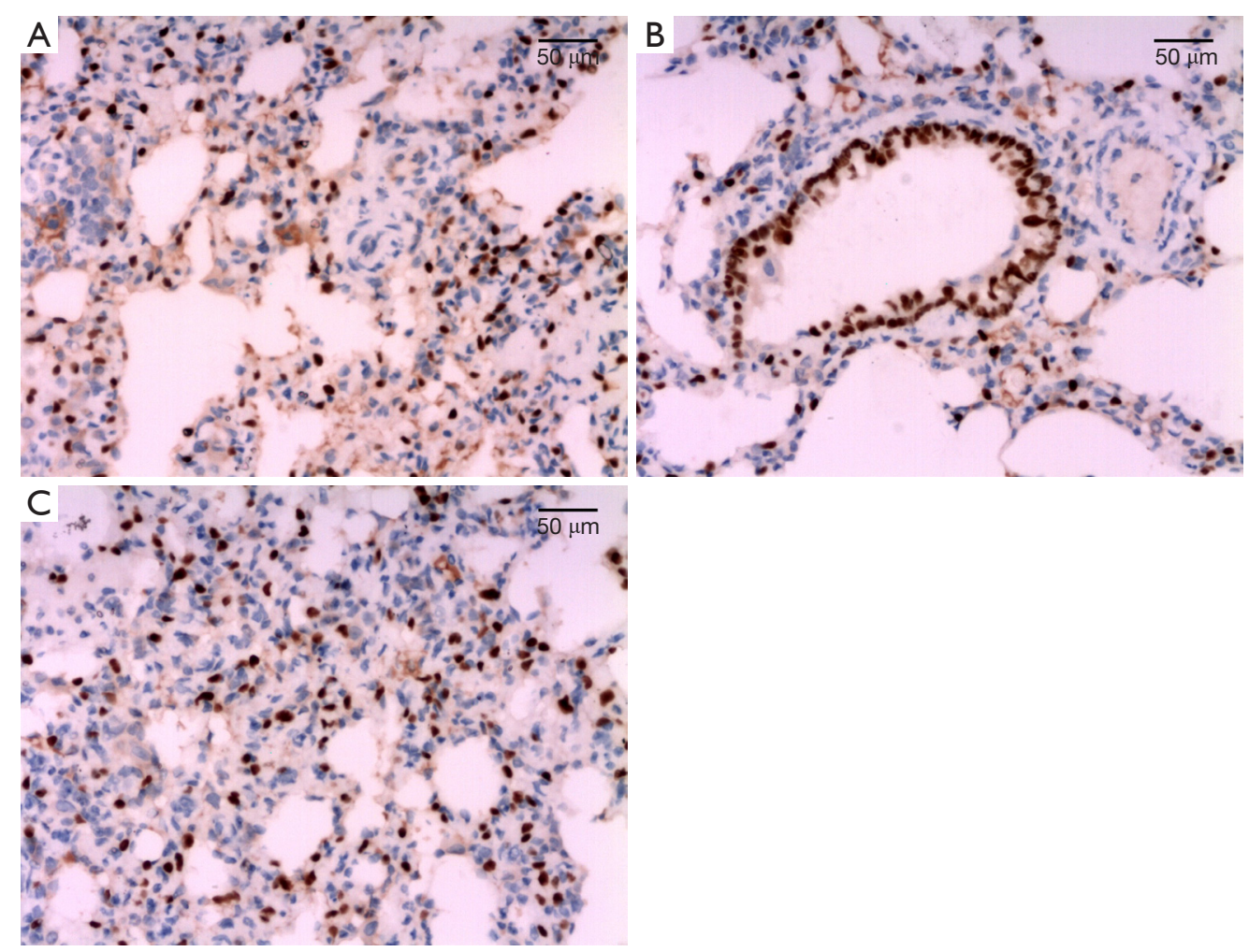

Figure 5 TUNEL staining of lung tissue at T2 time point in each group (200x). TUNEL, terminal deoxynucleotidyl transferase-mediated dUTP nick-end labeling. 
Acute lung injury (ALI) is a common complication after $\mathrm{CPB}$. $\mathrm{CPB}$ is a frequently used technique during heart surgery. However, ALI is one of the most severe complications that occurs during and after CPB (15). Approximately $2 \%$ to $3 \%$ of patients who undergo cardiac surgery suffer acute respiratory distress syndrome (ARDS) under $\mathrm{CPB}$, resulting in the mortality rates from $50 \%$ to $71.6 \%(16)$.

HO-1 expression can confer cytoprotection in many lung and vascular injury and disease models $(17,18)$. In recent years, intensive investigation has focused on potential therapeutic tools to manipulate apoptosis, inflammation, and oxidative stress in order to alter the outcome of pulmonary or vascular diseases. Previous studies have shown that intranasal administration with Lactococcus lactis secreting bioactive heme oxygenase-1 (LL-HO-1) significantly reduce hyperoxia-induced lung injury as demonstrated by a decreased wet/dry ratio, myeloperoxidase activity in lung tissue, tumor necrosis factor alpha (TNF- $\alpha$ ) levels in bronchoalveolar lavage (BAL) fluid, and attenuated lung injury scores. HO-1 levels in nasal mucosa and interleukin-10 concentrations in BAL fluid significantly increased, this demonstrated intranasal administration of LL-HO-1 protected against hyperoxiainduced lung damage, apparently through attenuation of inflammation (19). Induction of HO-1 by hemin pretreatment significantly ameliorated the L-arginine-induced pancreatitis and associated pulmonary complications may be due to its anti-inflammatory and antioxidant properties by increasing serum levels of amylase, lipase, TNF- $\alpha$, nitric oxide, and histo-architectural changes in pancreas and lungs (20). Hsu et al. (21) confirmed that Ginkgo biloba extract (EGb) conferred protection from oxidative stress-related apoptosis induced by cigarette smoke extract (CSE) in human pulmonary artery endothelial cells and its therapeutic effects depended on transcriptional upregulation of HO-1 by EGb via the extracellular signalregulated protein kinases (ERK), c-Jun N-terminal kinase (JNK) and p38 [three major mitogen-activated protein kinases (MAPKs)]/nuclear factor erythroid-2-related factor 2 (Nrf2) pathway. There have been many reports showing that HO-1 induction is effective for ovalbumin-induced neutrophilic airway inflammation by inhibiting Th17 cellmediated immune response (22), hydrogen peroxideinduced cytotoxicity in lung epithelial cell lines (23), and erythrocyte-induced inflammatory injury in lung in rat models (24).

In the present study, we for the first time, demonstrated that HO-1 exerted an anti-apoptotic activity against lung injury after $\mathrm{CPB}$. Apoptosis is one of the most important factors causing lung injury in the early stage of lung ischemia-reperfusion. Apoptotic cells in lung tissue mainly distribute in type II alveolar epithelial cells, and also in airway epithelial cells of lung tissue (25-27). In present study, apoptotic cells increased gradually after CPB, indicating that apoptosis after ischemia-reperfusion were involved in the process of lung injury, further suggesting that inhibiting apoptosis may play a protective role in lung ischemia-reperfusion injury. Bcl-2 family plays an important role in the process of apoptosis. Bcl-2 is an oncogene and an integral anti-apoptotic gene in the body, which can inhibit cell death caused by many cytotoxic factors $(28,29)$. Current studies indicate that the mechanism of Bcl-2 inhibiting apoptosis may be related to the following effects (30-32): inhibiting transmembrane flow of Calcium ion (33); playing an anti-oxidative role by reducing the production of oxygen free radicals and lipid peroxidation; inhibiting mitochondrial permeability changes, blocking the release of apoptotic protein activator cytochrome $\mathrm{C}$ and apoptotic inducible factor from mitochondrion $(34,35)$; Bcl-2 can also bind to proteins outside the Bcl-2 family and play an anti-apoptotic role together; it's function may include maintenance of mitochondrial integrity to prevent apoptosis protease-activating factor activation to inhibit its proapoptotic effect. In the present study, we confirmed that the expression of anti-apoptotic protein Bcl-2 in rat lung tissue after $\mathrm{CPB}$ in $\mathrm{CoPP}$ group was significantly higher than those in control group and CoPP plus $\mathrm{ZnPP}$ group, this indicated that the percentage of apoptotic cells in rat lung tissue in CoPP group decreased significantly after CPB. Therefore, this study confirmed that HO-1 could reduce and inhibit apoptosis of lung tissue during CPB in rats. Its anti-apoptotic effect may be achieved by upregulating the expression of anti-apoptotic protein Bcl-2 in lung tissue. In consistent with our result, Liu et al. (36) had found that HO-1 could reduce the apoptosis rate of type II alveolar epithelial cells (AEC II) in rats with hyperoxiainduced acute lung injury (HALI), which may be related to the expressions of apoptosis related proteins Bcl-2 and caspase-3. The expression of Bcl-2 in CoPP plus $\mathrm{ZnPP}$ group was significantly lower than that in the CoPP group, suggesting that the anti-apoptotic effect of HO-1 could be reversed by specific inhibitors of HO-1.

The present study has several limitations. First, we only investigated the protective effect of HO-1 against CPBinduced apoptosis in rat lung tissue, more investigation is 
needed on other protective effects such as anti-inflammatory and antioxidative. Second, some previous studies noted that HO-1 exhibited anti-inflammatory and anti-apoptotic functions partly mediated by the activation of the p38 MAPK and nuclear factor erythroid 2-related factor 2 (Nrf2) signaling pathway $(37,38)$. Thus, the underlying protective mechanism by which HO-1 play an anti-apoptotic effect and alleviate lung tissue injury after $\mathrm{CPB}$ is not fully expounded and requires further exploration. Furthermore, more apoptosis related proteins such as caspase-9, Fas, P53, and associated mechanisms, and preclinical data in vivo should be studied. So, we just demonstrated the basic information on the effect of HO-1 against CPB-induced apoptosis in lung injury in rat model.

In conclusion, cobalt protoporphyrin can induce of the high expression HO-1 in lung tissue and thus increase its activity, and it still maintains high expression even after complicated pathophysiological process such as CPB. The high expression of endogenous HO-1 has a certain antiapoptotic effect in lung injury induced by $\mathrm{CPB}$, so as to alleviate lung tissue injury after CPB. Its anti-apoptotic effect may be achieved by up-regulating of the expression of anti-apoptotic protein Bcl-2. Therefore, inducing the high expression of endogenous HO-1 in lung tissues through various mechanisms can provide a new way for the protection of lung function during $\mathrm{CPB}$ in cardiac surgery.

\section{Acknowledgments}

Funding: This work was supported by the project "Scientific research project" of Qingdao Municipal Bureau of health (No: 2013-WSZD012).

\section{Footnote}

Conflicts of Interest: All authors have completed the ICMJE uniform disclosure form (available at http://dx.doi. org/10.21037/jtd.2020.03.48). The authors have no conflicts of interest to declare.

Ethical Statement: The authors are accountable for all aspects of the work in ensuring that questions related to the accuracy or integrity of any part of the work are appropriately investigated and resolved. All protocols were approved by the Qingdao Institute for Biochemical Drug Control Animal Care and Use committee and by the Ethics Committee of Qingdao Municipal hospital affiliated to
Qingdao University (Qingdao, China), and the care and handling of the animals were in accordance with the Guide for the Care and Use of Laboratory Animals of the National Institutes of Health.

Open Access Statement: This is an Open Access article distributed in accordance with the Creative Commons Attribution-NonCommercial-NoDerivs 4.0 International License (CC BY-NC-ND 4.0), which permits the noncommercial replication and distribution of the article with the strict proviso that no changes or edits are made and the original work is properly cited (including links to both the formal publication through the relevant DOI and the license). See: https://creativecommons.org/licenses/by-nc-nd/4.0/.

\section{References}

1. Wei J, Fan G, Zhao H, et al. Heme oxygenase-1 attenuates inflammation and oxidative damage in a rat model of smoke-induced emphysema. Int J Mol Med 2015;36:1384-92.

2. Takahashi T, Shimizu H, Morimatsu H, et al. Heme Oxygenase-1 is an essential cytoprotective component in oxidative tissue injury induced by hemorrhagic shock. J Clin Biochem Nutr 2009;44:28-40.

3. Liu PL, Liu JT, Kuo HF, et al. Epigallocatechin gallate attenuates proliferation and oxidative stress in human vascular smooth muscle cells induced by interleukin- $1 \beta$ via heme oxygenase-1. Mediators Inflamm 2014;2014:523684.

4. Ryter SW, Kim HP, Nakahira K, et al. Protective functions of heme oxygenase-1/carbon monoxide in the respiratory system. Antioxid Redox Signal 2007;9:2157-73.

5. Yamazaki S, Inamori S, Nakatani T, et al. Activated protein $\mathrm{C}$ attenuates cardiopulmonary bypass-induced acute lung injury through the regulation of neutrophil activation. J Thorac Cardiovasc Surg 2011;141:1246-52.

6. Apostolakis EE, Koletsis EN, Baikoussis NG, et al. Strategies to prevent intraoperative lung injury during cardiopulmonary bypass. J Cardiothorac Surg 2010;5:1.

7. Namba F, Go H, Murphy JA, et al. Expression level and subcellular localization of heme oxygenase-1 modulates its cytoprotective properties in response to lung injury: a mouse model. PLoS One 2014;9:e90936.

8. Dennery PA. Heme oxygenase in neonatal lung injury and repair. Antioxid Redox Signal 2014;21:1881-92.

9. Huang HR, Zhang L, Li DM, et al. Lung injury after cardiopulmonary bypass in rats. Military Medical Journal of Southeast China 2014;16:113-6. 
10. Fu DR, Kato D, Watabe A, et al. Prognostic utility of apoptosis index, Ki-67 and survivin expression in dogs with nasal carcinoma treated with orthovoltage radiation therapy. J Vet Med Sci 2014;76:1505-12.

11. Tan Z, Wang H, Sun J, et al. Effects of propofol pretreatment on lung morphology and heme oxygenase-1 expression in oleic acid-induced acute lung injury in rats. Acta Cir Bras 2018;33:250-8.

12. Chen X, Wang Y, Xie X, et al. Heme Oxygenase-1 Reduces Sepsis-Induced Endoplasmic Reticulum Stress and Acute Lung Injury. Mediators Inflamm 2018;2018:9413876.

13. Unuma K, Aki T, Matsuda S, et al. Inducer of heme oxygenase-1 cobalt protoporphyrin accelerates autophagy and suppresses oxidative damages during lipopolysaccharide treatment in rat liver. Hepatol Res 2013;43:91-6.

14. Yin H, Li X, Yuan B, et al. Heme oxygenase-1 ameliorates LPS-induced acute lung injury correlated with downregulation of interleukin-33. Int Immunopharmacol 2011;11:2112-7.

15. Markou T, Chambers DJ. Lung injury after simulated cardiopulmonary bypass in an isolated perfused rat lung preparation: Role of mitogen-activated protein kinase/ Akt signaling and the effects of theophylline. J Thorac Cardiovasc Surg 2014;148:2335-44.

16. Wang Z, Hou L, Yang H, et al. Electroacupuncture Pretreatment Attenuates Acute Lung Injury Through $\alpha 7$ Nicotinic Acetylcholine Receptor-Mediated Inhibition of HMGB1 Release in Rats After Cardiopulmonary Bypass. Shock 2018;50:351-9.

17. Morse D, Lin L, Choi AM, et al. Heme oxygenase-1, a critical arbitrator of cell death pathways in lung injury and disease. Free Radic Biol Med 2009;47:1-12.

18. Ryter SW, Alam J, Choi AM. Heme oxygenase-1/carbon monoxide: from basic science to therapeutic applications. Physiol Rev 2006;86:583-650.

19. Wu CY, Bermúdez-Humarán LG, Yue F, et al. Intranasal administration with recombinant Lactococcus lactis expressing heme oxygenase-1 reduces hyperoxiainduced lung inflammation in rat pups. Biotechnol Lett 2015;37:1203-11.

20. Aziz NM, Kamel MY, Rifaai RA. Effects of hemin, a heme oxygenase- 1 inducer in L-arginine-induced acute pancreatitis and associated lung injury in adult male albino rats. Endocr Regul 2017;51:20-30.

21. Hsu CL, Wu YL, Tang GJ, et al. ginkgo biloba extract confers protection from cigarette smoke extract-induced apoptosis in human lung endothelial cells: role of heme oxygenase-1. Pulm Pharmacol Ther 2009;22:286-96.

22. Zhang $\mathrm{Y}$, Zhang $\mathrm{L}, \mathrm{Wu}$ J, et al. Heme oxygenase-1 exerts a protective role in ovalbumin-induced neutrophilic airway inflammation by inhibitingTh17 cell-mediated immune response. J Biol Chem 2013;288:34612-26.

23. Hayashi Y, Matsushima M, Nakamura T, et al. Quercetin protects against pulmonary oxidant stress via heme oxygenase-1 induction in lung epithelial cells. Biochem Biophys Res Commun 2012;417:169-74.

24. Pang QF, Zhou QM, Zeng S, et al. Protective effect of heme oxygenase-1 on lung injury induced by erythrocyte instillation in rats. Chin Med J 2008;121:1688-92.

25. White LE, Cui Y, Shelak CM, et al. lung endothelial cell apoptosis during ischemic acute kidney injury. Shock 2012;38:320-7.

26. Deng C, Zhai Z, Wu D, et al. Inflammatory response and pneumocyte apoptosis during lung ischemia-reperfusion injury in an experimental pulmonary thromboembolism model. J Thromb Thrombolysis 2015;40:42-53.

27. Zhang C, Guo Z, Liu H, et al. Influence of levosimendan postconditioning on apoptosis of rat lung cells in a model of ischemia-reperfusion injury. PLoS One 2015;10:e0114963.

28. Guo HJ, Kang K, Liu HX, et al. Comparison of Antiapoptotic Potency between Acyanotic and Cyanotic Congenital Heart Disease-derived Human Mesenchymal Stem Cells in vitro. Chinese Journal of Clinical Thoracic and Cardiovascular Surgery 2016;23:1172-6.

29. Li Ch, Wu X, Sun R, et al. Croton tiglium extract induces apoptosis via bax/bcl-2 pathways in human lung cancer A549 cells. Asian Pac J Cancer Prev 2016;17:4893-8.

30. Park EJ, Chauhan AK, Min KJ, et al. Thymoquinone induces apoptosis through downregulation of c-FLIP and Bcl-2 in renal carcinoma Caki cells. Oncol Rep 2016;36:2261-7.

31. Liang S, Sun K, Wang Y, et al. Role of Cyt-C/caspases-9,3, $\mathrm{Bax} / \mathrm{Bcl}-2$ and the FAS death receptor pathway in apoptosis induced by zinc oxide nanoparticles in human aortic endothelial cells and the protective effect by alphalipoic acid. Chem Biol Interact 2016;258:40-51.

32. Zhang Q, Ma S, Liu B, et al. Chrysin induces cell apoptosis via activation of the $\mathrm{p} 53 / \mathrm{Bcl}-2 /$ caspase-9 pathway in hepatocellular carcinoma cells. Exp Ther Med 2016;12:469-74.

33. Vervliet T, Parys JB, Bultynck G. Bcl-2 proteins and calcium signaling: complexity beneath the surface. Oncogene 2016;35:5079-92.

34. Jia G, Wang Q, Wang R, et al. Tubeimoside-1 induces 
glioma apoptosis through regulation of $\mathrm{Bax} / \mathrm{Bcl}-2$ and the ROS/Cytochrome C/Caspase-3 pathway. Onco Targets Ther 2015;8:303-11.

35. Clerc P, Ge SX, Hwang H, et al. Drp1 is dispensable for apoptotic cytochrome c release in primed MCF10A and fibroblast cells but affects Bcl-2 antagonist-induced respiratory changes. Br J Pharmacol 2014;171:1988-99.

36. Liu G, Chen T, Chen B. Effect of heme oxygenase-1 on the apoptosis of type II alveolar epithelial cells in rats with hyperoxia-induced acute lung injury. Zhonghua Wei

Cite this article as: Sheng W, Yang H, Niu Z, Yin H. Antiapoptosis effect of heme oxygenase-1 on lung injury after cardiopulmonary bypass. J Thorac Dis 2020;12(4):1393-1403. doi: $10.21037 /$ jtd. 2020.03 .48
Zhong Bing Ji Jiu Yi Xue 2018;30:1001-5.

37. Zhang Z, Zhou J, Song D, et al. Gastrodin protects against LPS-induced acute lung injury by activating Nrf2 signaling pathway. Oncotarget 2017;8:32147-56.

38. Wang F, Meng Y, Zhang Y, et al. Ketamine reduces lipopolysaccharide-induced high-mobility group box-1 through heme oxygenase- 1 and nuclear factor erythroid 2-related factor 2/p38 mitogen-activated protein kinase. J Surg Res 2015;194:599-613. 